\title{
Proteomics-based identification of haptoglobin as a favourable serum biomarker for predicting long-term response to splenectomy in patients with primary immune thrombocytopenia
}

\author{
Chao-Xu Zheng ${ }^{1}$, Zhuang-Qi Ji ${ }^{1}$, Long-Juan Zhang ${ }^{2}$, Qiong Wen ${ }^{3}$, Liu-Hua Chen ${ }^{1}$, Jun-Feng Yu ${ }^{1}$ and Dong Zheng ${ }^{4^{*}}$
}

\begin{abstract}
Background: Splenectomy is the most effective treatment for patients with primary immune thrombocytopenia (ITP) who fail to respond to steroid therapy. Thus far, there is no effective means to predict the long-term haematological response of the procedure. The purpose of this study was to identify serum biomarkers as predictors of long-term response based on a proteomics approach.

Methods: The serum samples of ITP patients were collected before splenectomy and seven days after surgery. After depletion of the abundant serum proteins, pooled preoperative serum samples from four responders to splenectomy, four nonresponders and four healthy controls were subjected to two-dimensional gel electrophoresis (2-DE). Nine protein spots with at least a five-fold alteration in expression between responders and nonresponders were all identified as haptoglobin ( $\mathrm{Hp}$ ) by matrix-assisted laser desorption/ionisation time-of-flight (MALDI-TOF) mass spectrometer (MS) analysis. The validation of serum Hp expression was performed using enzyme-linked immunosorbent assays (ELISA) in thirty-seven responders, thirteen nonresponders and twenty-one healthy controls.

Results: The preoperative serum levels of $\mathrm{Hp}$ in the nonresponders $(925.9 \pm 293.5 \mu \mathrm{g} / \mathrm{ml})$ were significantly lower than those in the responders $(1417.4 \pm 315.0 \mu \mathrm{g} / \mathrm{ml}, p<0.001)$ and the healthy controls $(1409.1 \pm 354.2 \mu \mathrm{g} / \mathrm{ml}, p<0.001)$, while there was no significant difference between the latter two groups. The postoperative serum levels of $\mathrm{Hp}$ in responders and nonresponders were $(1414.1 \pm 225.0 \mu \mathrm{g} / \mathrm{ml})$ and $(952.9 \pm 202.4 \mu \mathrm{g} / \mathrm{ml})$, respectively. There were no significant differences between the serum $\mathrm{Hp}$ levels before and after surgery in both responders and nonresponders $(p>0.05)$. The preoperative serum levels of $\mathrm{Hp}$ did not significantly correlate with preoperative platelet count of the same blood samples $(r=0.244, p=0.087)$, while it positively correlated with postoperative peak platelet count $(r=0.622, p<0.001)$. The optimal cutoff value of preoperative serum Hp levels $(1173.80 \mu \mathrm{g} / \mathrm{ml})$ derived from the receiver operating characteristic (ROC) curve led to $78.4 \%$ sensitivity and $84.6 \%$ specificity.

Conclusions: These results suggest that serum Hp levels may serve as a favourable predictor for the long-term response to splenectomy in ITP and may help to understand the pathophysiological differences between responders and nonresponders.
\end{abstract}

Keywords: Primary immune thrombocytopenia, Splenectomy, Proteomics, Biomarkers, Haptoglobin

\footnotetext{
* Correspondence: zcxzd@tom.com

${ }^{4}$ Department of Haematology, The First Affiliated Hospital, Sun Yat-sen

University, Guangzhou 510080, China

Full list of author information is available at the end of the article
} 


\section{Background}

Primary immune thrombocytopenia (ITP), also known as primary immune thrombocytopenic purpura or idiopathic thrombocytopenic purpura, is an immunemediated acquired disease characterised by low platelet counts and bleeding complications in children and adults [1]. Patients with platelet counts persistently lower than $30 \times 10^{9} / \mathrm{L}$ are at risk for life-threatening bleeding. The main mechanisms of ITP are anti-platelet autoantibody-mediated platelet destruction and inhibition of thrombopoiesis [2]. Other mechanisms such as abnormal T-helper cells type 1 (Th1) and type 2 (Th2) responses, complement activation, and direct $\mathrm{T}$-cell cytotoxicity were also found in ITP patients [2].

The spleen has been considered the main site for the autoimmune processes in ITP pathophysiology [3]. Splenectomy has proven to be a preferred treatment for ITP patients who do not respond to glucocorticoid treatment or continue to need high-dose glucocorticoids to maintain a safe platelet count. The results of numerous studies indicate that approximately two-thirds of adult patients and 70 to 80 percent of children achieve a durable response to splenectomy [1]. However, splenectomy for ITP is often associated with the risk of major morbidity and mortality, and the long-term haematological outcomes of the procedure cannot be predicted through routinely available measures [4]. Some studies reported that several variables may predict a stable response to splenectomy including younger age [5-7], previous response to steroids $[6,7]$ and postoperative peak platelet count $[8,9]$. Other studies showed opposite results [1012]. Najean et al. found the site of autologous ${ }^{111}$ Inlabeled platelet sequestration to be a good prognostic parameter [13]. However, the techniques of isotope assessments are often qualitative, rather than quantitative, and many patients with nonsplenic sequestration also respond well to splenectomy [4]. Hence, the assessments of platelet sequestration are not widely accepted. The fear of failure to respond to the splenectomy renders many patients reluctant to undergo surgery and haematologists hesitant to recommend the surgery. Therefore, it is imperative to identify a preoperative serum biomarker that can serve as a predictor of good response to splenectomy and help patients and physicians with the decision of using surgery to treat ITP.

In this study, we used two-dimensional gel electrophoresis (2-DE) technology coupled with matrix-assisted laser desorption/ionisation time-of-flight (MALDI-TOF) mass spectrometer (MS) analysis to identify differentially expressed proteins in ITP patients with different responses to splenectomy. The identified proteins were further confirmed by enzyme-linked immunosorbent assays (ELISA) to evaluate their values in predicting the long-term response to splenectomy.

\section{Methods}

\section{Patients and healthy controls}

This study included fifty-eight patients (twenty males and thirty-eight females; mean age $38.1 \pm 15.6$ years; age range 16-70 years) undergoing laparoscopic splenectomy for chronic ITP at the Department of Minimal Invasive Surgery, the First Affiliated Hospital of Sun Yatsen University, between May 2007 and April 2011. All patients recovered well without any major postoperative morbidity. The diagnosis of ITP was made according to the guidelines published by the British Committee for Standards in Haematology General Haematology Task Force [14]. Other possible causes of thrombocytopenia were ruled out. Routine blood tests (including haemoglobins, reticulocyte counts, bilirubin levels, and lactate dehydrogenase) were performed for all patients enrolled in this study. Direct Coombs testings had been done in the patients presenting with anaemia. No evidence of haemolysis was found in these patients and Evans syndrome was excluded from this corhort. The indications for splenectomy in these patients included those did not respond to steroids at all and/or the requirement of prolonged use of high dose steroids to maintain a platelet count over $30 \times 10^{9} / \mathrm{L}$. All patients received corticosteroids or immunosuppressive agent treatment until they underwent laparoscopic splenectomy. The dosages of steroids were then reduced gradually after surgery. The blood samples of ITP patients were collected before splenectomy and seven days after surgery. None of the patients enrolled in this study received any platelet transfusions, intravenous immunoglobulin or anti-RhD immunoglobulin (anti-D) treatments for at least two weeks before the collection of the preoperative blood samples. Twenty-five age- and sex-matched healthy subjects served as the controls. The study was approved by the Ethical Committee of the First Affiliated Hospital of Sun Yat-sen University. Informed consent was obtained from each patient and healthy subject.

\section{Definition of long-term response to splenectomy}

All of the patients were followed up after splenectomy throughout the study. In this study, we adopted the definition of haematological outcome suggested recently by the international working group [1]. Complete response (CR) was defined as a platelet count $\geq 100 \times 10^{9} / \mathrm{L}$ and the absence of bleeding. Response (R) is defined as any platelet count between 30 and $100 \times 10^{9} / \mathrm{L}$ and at least a two-fold increase in the baseline count and the absence of bleeding. No response (NR) is defined as any platelet count lower than $30 \times 10^{9} / \mathrm{L}$ or less than a two-fold increase in the baseline platelet count or the presence of bleeding. In this study, the long-term response to splenectomy was defined as a complete response or response from twelve months to the last follow-up without any 
medications. For the statistical analysis, the patients were subdivided into the responder $(\mathrm{CR}+\mathrm{PR})$ group $(n=41)$ and the nonresponder (NR) group $(n=17)$ according to the long-term follow-up results.

\section{Serum sample preparation}

Fresh whole blood samples were collected during a fasting state in the early morning. All samples were transported on ice and centrifuged immediately at $3000 \mathrm{~g}$ for $15 \mathrm{~min}$ at $4^{\circ} \mathrm{C}$. The supernatants were divided into $500 \mu \mathrm{l}$ aliquots and stored at $-80^{\circ} \mathrm{C}$ until further analysis. Blood samples from four patients in the responder group, four in the nonresponder group, and four healthy controls were used for the screening study. The serum samples from the other thirty-seven responders, thirteen nonresponders, and twenty-one healthy controls were used for the validation study.

Highly abundant proteins in serum were depleted using a Proteoprep Blue Albumin and IgG Depletion Kit (Sigma-Aldrich, Missouri, USA) according to the manufacturer's instructions. The final protein concentration was detected using the Bio-Rad Protein Assay technique.

\section{Two-dimensional electrophoresis and image analyses}

Isoelectric focusing (IEF) was performed on an Ettan IPGphor III IEF System (Amersham Bioscience, Uppsala, Sweden) at $20^{\circ} \mathrm{C}$. Immobiline DryStrips $(18 \mathrm{~cm}$ long, $\mathrm{pH}$ 4-7) (Amersham Bioscience, Uppsala, Sweden) were rehydrated actively at $30 \mathrm{~V}$ for $12 \mathrm{~h}$ with $750 \mu \mathrm{g}$ of depleted serum protein that was premixed with rehydration buffer containing $7 \mathrm{M}$ urea, $2 \mathrm{M}$ thiourea, 2\% 3-[(3-cholamidopropyl) dimethylammonio]-1-propanesulfonate (CHAPS), 0.5\% (v/v) ampholytes ( $\mathrm{pH} 4-7$ ), $20 \mathrm{mM}$ dithiothreitol (DTT) and a trace of bromophenol blue (making the final volume of $350 \mu \mathrm{l}$ ). IEF was conducted with gradient voltages of $200 \mathrm{~V}$ for $1 \mathrm{~h}, 1000 \mathrm{~V}$ for $1 \mathrm{~h}$, a $3 \mathrm{~h}$ linear ramp up to $10,000 \mathrm{~V}$, and final focusing at $10,000 \mathrm{~V}$ for a total of $110,000 \mathrm{Vh}$. The immobilized $\mathrm{pH}$ gradient (IPG) strips were equilibrated in buffer 1 (75 mM Tris-HCl, pH 8.8, $6 \mathrm{M}$ urea, 30\% (v/v) glycerol, $2 \%(\mathrm{w} / \mathrm{v})$ sodium dodecyl sulfate (SDS), 1\% (w/v) DTT and a trace of bromophenol blue) for $15 \mathrm{~min}$ and then subsequently alkylated in buffer $2(75 \mathrm{mM}$ Tris- $\mathrm{HCl}$ $\mathrm{pH}$ 8.8, $6 \mathrm{M}$ urea, 30\% (v/v) glycerol, 2\% (w/v) SDS, 2.5\% $(\mathrm{w} / \mathrm{v})$ iodoacetamide and a trace of bromophenol blue) for 15 min. The IPG strip was then transferred to a $12.5 \%$ SDS polyacrylamide gel, and the second dimensional separation was performed in an Ettan DALT six Electrophoresis Unit (Amersham Bioscience, Uppsala, Sweden) with the power set at $1 \mathrm{w} /$ gel for $1 \mathrm{~h}$ followed by $15 \mathrm{w} /$ gel until the tracking dye migrated to within $1 \mathrm{~cm}$ of the bottom of the gel at $15^{\circ} \mathrm{C}$. The gels were stained with colloidal coomassie as described in the manual.
The 2-DE gel images were analysed using Image Master 2D Platinum 6.0 software (Amersham Bioscience, Uppsala, Sweden). The relative volumes of spots were used for comparison between two patient groups. Our study mainly focused on the highly differentially expressed proteins whose expressions were strongly associated with response to splenectomy in ITP patients. As described by Zhang et al. [15], the criterion for highly differentially expressed protein was also set as at least a five-fold change in spot volume between the two matched sets in our study. Only those highly differentially expressed protein spots (at least five-fold alterations in expression in responders versus nonresponders) were chosen for further analysis by MALDI-TOF/TOF MS.

\section{In-gel digestion and MALDI-TOF/TOF MS analyses}

Protein spots of interest were excised manually from 2-DE gels, destained with $15 \mathrm{mM}$ potassium ferricyanide and $50 \mathrm{mM}$ sodium thiosulfate, and subsequently dehydrated in $100 \%$ acetonitrile. Each sample was then treated with $2 \mu \mathrm{l}(25 \mathrm{ng} / \mu \mathrm{l})$ of modified porcine trypsin in $25 \mathrm{mM}$ ammonium bicarbonate $(\mathrm{pH} 8)$ overnight at $37^{\circ} \mathrm{C}$. The trypsin solutions were collected for mass spectrometry analysis.

Protein identification was performed with an Ultraflex III mass spectrometer (Bruker Daltonics, Bremen, Germany) and operated in the positive ion reflectron mode. A saturated solution of $\alpha$-cyano-4-hydroxycinnamic acid in $50 \%$ acetonitrile and $0.1 \%$ trifluoroacetic acid was used as the matrix. A standard peptide mixture with a mass range 800-4000 Da (Bruker Daltonics, Germany) was used for external calibration. The subsequent MS/MS analysis was performed in a data-dependent manner, and the five most abundant ions fulfilling certain pre-set criteria were subjected to LIFT for a post-source decay analysis.

Peptide mass fingerprints (PMFs) and MS/MS analyses were searched by the BioTools software (version 3.0, Bruker Daltonics, Germany) against the SwissProt protein database. The search parameters were as follows: trypsin digestion with maximum one missed cleavage; carbamidomethylation of cysteine as fixed modification and oxidation of methionine as variable modification; peptide mass tolerance, $\pm 100 \mathrm{ppm}$; fragment mass tolerance, $\pm 0.5 \mathrm{Da}$; peptide charge, +1 ; and monoisotopic mass. Protein identifications were accepted when the peptide score was higher than the threshold value $(p<0.05)$, and manual interpretation was used to confirm agreement between the spectra and peptide sequence.

\section{Validation of identified proteins by ELISA}

To validate the haptoglobin ( $\mathrm{Hp}$ ) expression in serum, serum samples from ITP patients and healthy controls were analysed by ELISA. The Hp levels of serum samples collected seven days after surgery were also 
evaluated at the same time. The concentrations of $\mathrm{Hp}$ in serum were determined using an AssayMax human $\mathrm{Hp}$ ELISA kit according to the manufacturer's protocol (Assaypro, Winfield, MO, USA).

\section{Statistical analysis}

Statistical analysis was carried out using SPSS 16.0 for Windows software (SPSS Inc., Chicago, IL, USA). Comparisons of gender and previous response to steroids between two patient groups were carried out using the chi-square test. Continuous variables were expressed as mean \pm standard deviation (SD). Comparisons were performed using the Mann-Whitney test between two independent groups, or one-way ANOVA followed by the least-significant difference test for three groups. The changes of the serum Hp levels before and after surgery in responders and nonresponders were analysed with Wilcoxon test. Correlation between parameters was assessed by calculating the Pearson's correlation coefficient. Receiver operating characteristic (ROC) curve was used to evaluate the predictive value of preoperative serum levels of $\mathrm{Hp}$ for long-term haematological outcomes of surgery. The area under the curve (AUC) with a $95 \%$ confidence interval (CI) was computed. Sensitivity and specificity were calculated according to different cutoff values. A $P$ value less than 0.05 was considered statistically significant.

\section{Results}

\section{Study population}

Table 1 summarises the baseline clinical characteristics of fifty-eight patients. There were no significant differences in the age, gender, previous response to steroids, disease duration before the surgery, preoperative platelet count or the duration of follow-up between the responder and nonresponder groups. However, a significantly higher postoperative peak platelet count was observed in the responders compared to the nonresponders $(P<0.001)$.

\section{Identification of Hp by 2-DE separation and MALDI-TOF/ TOF-MS analyses}

Pooled preoperative serum proteins from four patients in the responder group, four in the nonresponder group, and four healthy controls were subjected to 2-DE separation. Two-dimensional electrophoresis was performed four times per sample to minimise gel-to-gel variations. Figure $1 \mathrm{~A}, 1 \mathrm{~B}$, and $1 \mathrm{C}$ show original $2 \mathrm{D}$ gel images for all samples of the three groups and identify a number of distinct protein spots. The enlarged images of regions 1-3 in the corresponding 2-DE gels reveal significant differential changes for some of the potential novel biomarkers (spots a-i, Figure 1D). By quantitative comparison of spot volumes, nine protein spots (spots a-i, Figure 2) were found to be down-regulated more than five-fold in the nonresponders when compared with the responders.

These nine protein spots were then excised from the gels and analysed by MALDI-TOF/TOF-MS. The results revealed that all of these protein spots were identified as $\mathrm{Hp}$ with different isoelectric points $(\mathrm{p} I)$ and molecular weights (MW) (Table 2). Figure 3 is a representative MALDI-TOF peptide mass fingerprint spectrum of trypsin-digested spot $\mathrm{b}$, which was remarkably downregulated in the nonresponders and was later identified as Hp.

\section{Decreased expression of $\mathrm{Hp}$ in the serum of nonresponders}

ELISA was further performed to validate the results of the 2-DE. As shown in Figure 4, the preoperative serum levels of $\mathrm{Hp}$ in thirty-seven responders, thirteen nonresponders, and twenty-one healthy controls were (1417.4 \pm $315.0 \mu \mathrm{g} / \mathrm{ml}, 95 \%$ CI: $1312.3-1522.4 \mu \mathrm{g} / \mathrm{ml}),(925.9 \pm 293.5$ $\mu \mathrm{g} / \mathrm{ml}, 95 \%$ CI:748.5-1103.2 $\mu \mathrm{g} / \mathrm{ml})$, and $(1409.1 \pm 354.2$ $\mu \mathrm{g} / \mathrm{ml}, 95 \%$ CI: $1247.9-1570.3 \mu \mathrm{g} / \mathrm{ml})$, respectively. Oneway ANOVA analysis showed that the preoperative serum levels of $\mathrm{Hp}$ in the nonresponders were significantly lower than those in the responders $(p<0.001)$ and healthy controls $(p<0.001)$. There was no significant difference in the preoperative serum levels of $\mathrm{Hp}$

Table 1 Baseline Characteristics of Patients

\begin{tabular}{|c|c|c|c|}
\hline Variables & $\begin{array}{l}\text { Responder group } \\
(\mathrm{n}=41)\end{array}$ & $\begin{array}{l}\text { Nonresponder group } \\
(n=17)\end{array}$ & $P$ value \\
\hline Age, year & $36.4 \pm 14.9$ & $42.3 \pm 16.9$ & 0.203 \\
\hline Gender (male/female) & $13 / 28$ & $7 / 10$ & 0.490 \\
\hline Previous response to steroids (response/resistance) & $21 / 20$ & $5 / 12$ & 0.128 \\
\hline Disease duration, months & $35.9 \pm 34.1$ & $30.9 \pm 31.4$ & 0.851 \\
\hline Preoperative platelet count $\left(\times 10^{9} / \mathrm{L}\right)$ & $29.9 \pm 28.4$ & $18.0 \pm 10.4$ & 0.090 \\
\hline Postoperative peak platelet count $\left(\times 10^{9} / \mathrm{L}\right)$ & $439.9 \pm 171.0$ & $201.1 \pm 132.6$ & $<0.001$ \\
\hline Follow-up, months & $34.4 \pm 13.4$ & $35.3 \pm 13.9$ & 0.824 \\
\hline
\end{tabular}




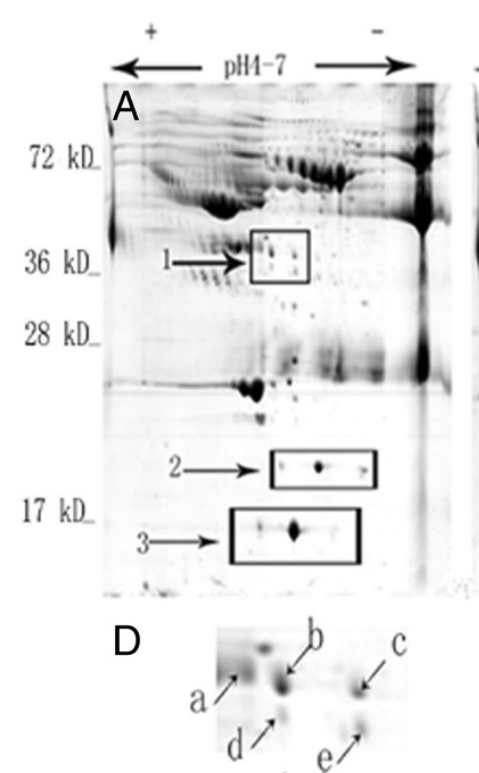

(A1)

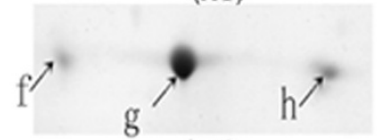

(A2)

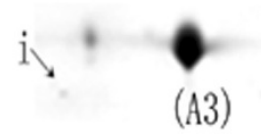

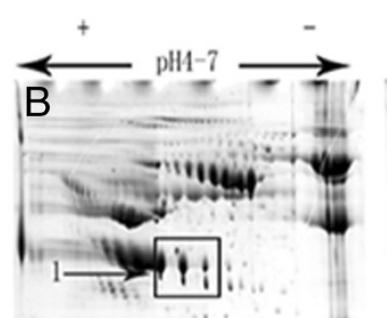
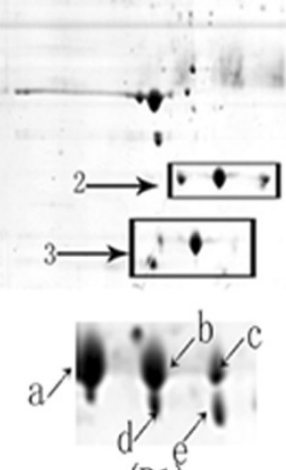

$(\mathrm{B} 1)$

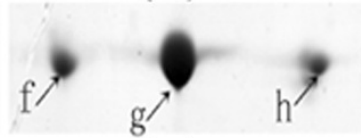

(B2)

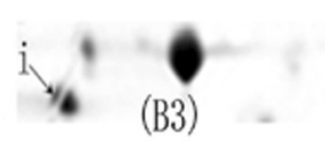

(B3)
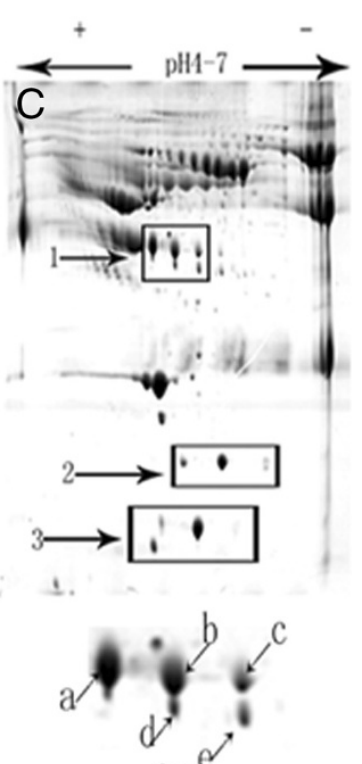

(C1)

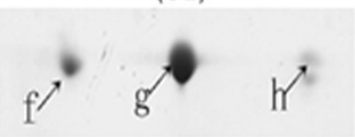

(C2)

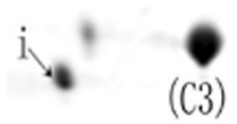

Figure 1 Differentially expressed protein spots identified by 2-DE image analysis. The original 2-DE images representing all protein spots present in serum samples from the nonresponder group (A), the responder group (B), and the healthy control group (C). The enlarged images (D) showing the magnified regions 1-3 of the corresponding 2-DE gels. Nine identified protein spots (a-i, arrows showing the corresponding locations) with significantly differential expressions among the three groups were visualised. Protein spots a to i showed obviously decreased expressions in the nonresponders compared with the responders and healthy controls.

between the responders and healthy controls $(p>0.05)$. The postoperative serum levels of $\mathrm{Hp}$ in the responders and the nonresponders were $(1414.1 \pm 225.0 \mu \mathrm{g} / \mathrm{ml}, 95 \%$ CI: $1339.1-1489.1 \mu \mathrm{g} / \mathrm{ml})$ and $(952.9 \pm 202.4 \mu \mathrm{g} / \mathrm{ml}, 95 \%$ CI: $830.6-1075.2 \mu \mathrm{g} / \mathrm{ml}$ ), respectively. There were no significant differences between the serum $\mathrm{Hp}$ levels before and after surgery in both responders and nonresponders $(p>0.05)$. Pearson's correlation analysis showed that the preoperative serum levels of $\mathrm{Hp}$ did not significantly correlate with preoperative platelet count of the same blood samples collected for this study in ITP patients $(r=0.244$, $p=0.087$ ), while a positive correlation was found between the preoperative serum $\mathrm{Hp}$ levels and postoperative peak platelet count $(\mathrm{r}=0.622, p<0.001)$.

\section{Predictive value of preoperative serum levels of $\mathrm{Hp}$}

Using the ROC curve method, we evaluated the predictive value of the preoperative Serum Hp levels for longterm response to splenectomy. As showed in Figure 5, AUC was 0.867 (95\% CI: 0.764-0.970), indicating that the preoperative Serum levels of Hp was a good predictor to differentiate responders from nonresponders. Table 3 showed the sensitivity and specificity of different cutoff values. Based on the maximum Youden index (sensitivity+specificity-1), the optimal cutoff value from the ROC curve, $\mathrm{Hp} \geq 1173.80 \mu \mathrm{g} / \mathrm{ml}$, was chosen. When this value was set, the sensitivity was $78.4 \%$ and the specificity was $84.6 \%$ for discriminating responders from nonresponders.

\section{Discussion}

Comprehensive analysis of the changes in serum proteomes are an important part of broad evaluations of the diagnosis, prognosis and therapeutic response of progressing diseases, such as autoimmune disorders, cardiovascular diseases, and cancers. With commonly used proteomic approaches, it is feasible to discover differentially expressed proteins in samples from patients that are likely to be involved in the autoimmune process or serve as biomarkers that correlate with disease or 


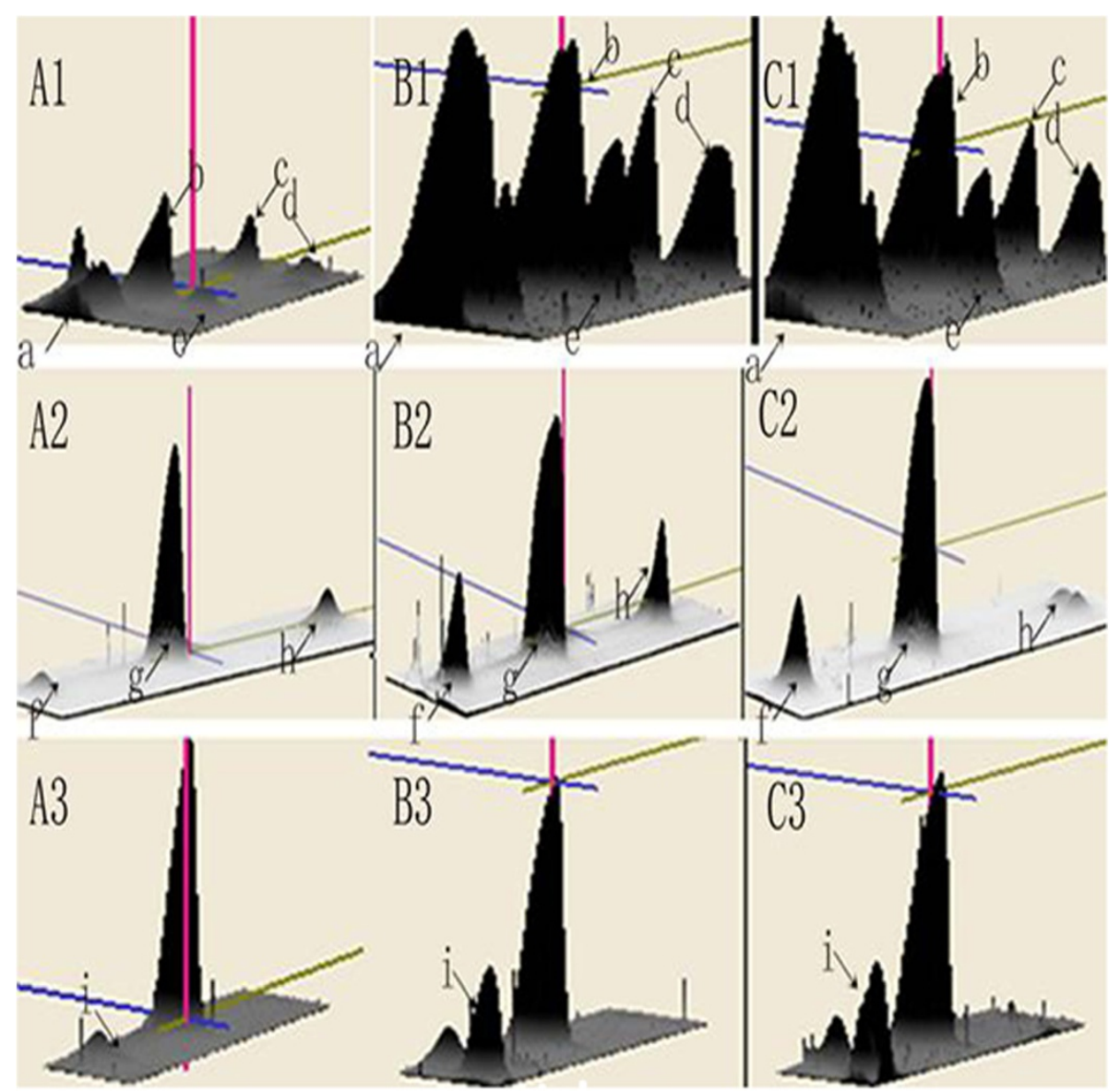

Figure 2 3-D view of highly differentially expressed proteins. The computational analysis of the images with Image Master 2D Platinum 6.0 software allowed for the detection of protein volumes. Significant changes of more than 5-fold were found in the protein spots (spots a to i) of the magnified regions 1-3 of the corresponding 2-DE gels among the nonresponder group (A), the responder group (B), and the healthy control group $(\mathbf{C})$. The differentially expressed proteins were down-regulated in the nonresponders compared with the responders and healthy controls.

therapeutic outcomes [16,17]. To date, only one proteomic-based study for biomarkers has been reported in ITP patients. In the study, one-dimensional gel electrophoresis was used to separate serum proteins in ITP patients, non-ITP patients with thrombocytopenia and healthy controls [18]. Quantification of the serum proteins identified by liquid chromatography-tandem mass spectrometric (LC-MS/MS) analysis showed that the serum ceruloplasmin levels in ITP patients were statistically significantly higher than in non-ITP patients and

Table 2 Identification of differentially expressed proteins by MALDI-TOF/TOF

\begin{tabular}{llllllllc}
\hline $\begin{array}{l}\text { Spot } \\
\text { number }\end{array}$ & $\begin{array}{l}\text { Protein } \\
\text { description }\end{array}$ & $\begin{array}{l}\text { Accession } \\
\text { number }\end{array}$ & MS method & $\begin{array}{l}\text { MASCOT } \\
\text { score }\end{array}$ & $\begin{array}{l}\text { Matched } \\
\text { peptides }\end{array}$ & $\begin{array}{l}\text { Sequence } \\
\text { coverage, \% }\end{array}$ & MW (kD)/pl & $\begin{array}{l}\text { Fold change (responder/ } \\
\text { nonresponder, n=4) }\end{array}$ \\
\hline a & Haptoglobin & P00738 & MS,MS/MS & 84,92 & 12,2 & $34 \%, 5 \%$ & $42.1 / 5.08$ & 8.11 \\
b & Haptoglobin & P00738 & MS,MS/MS & 67,116 & 12,3 & $33 \%, 8 \%$ & $42.2 / 5.21$ & 5.94 \\
C & Haptoglobin & P00738 & MS,MS/MS & 103,90 & 10,2 & $32 \%, 6 \%$ & $42.0 / 5.37$ & 5.50 \\
d & Haptoglobin & P00738 & MS,MS/MS & 92,100 & 12,2 & $32 \%, 6 \%$ & $39.1 / 5.21$ & 5.60 \\
e & Haptoglobin & P00738 & MS,MS/MS & 109,66 & 10,2 & $32 \%, 6 \%$ & $38.7 / 5.38$ & 7.30 \\
f & Haptoglobin & P00738 & MS/MS & 46 & 2 & $6 \%$ & $16.9 / 5.40$ & 9.57 \\
g & Haptoglobin & P00738 & MS/MS & 129 & 1 & $6 \%$ & $17.1 / 5.68$ & 5.21 \\
h & Haptoglobin & P00738 & MS/MS & 94 & 2 & $7 \%$ & $16.9 / 6.07$ & 5.35 \\
i & Haptoglobin & P00738 & MS/MS & 54 & 1 & $3 \%$ & $11.9 / 5.13$ & \\
\hline
\end{tabular}




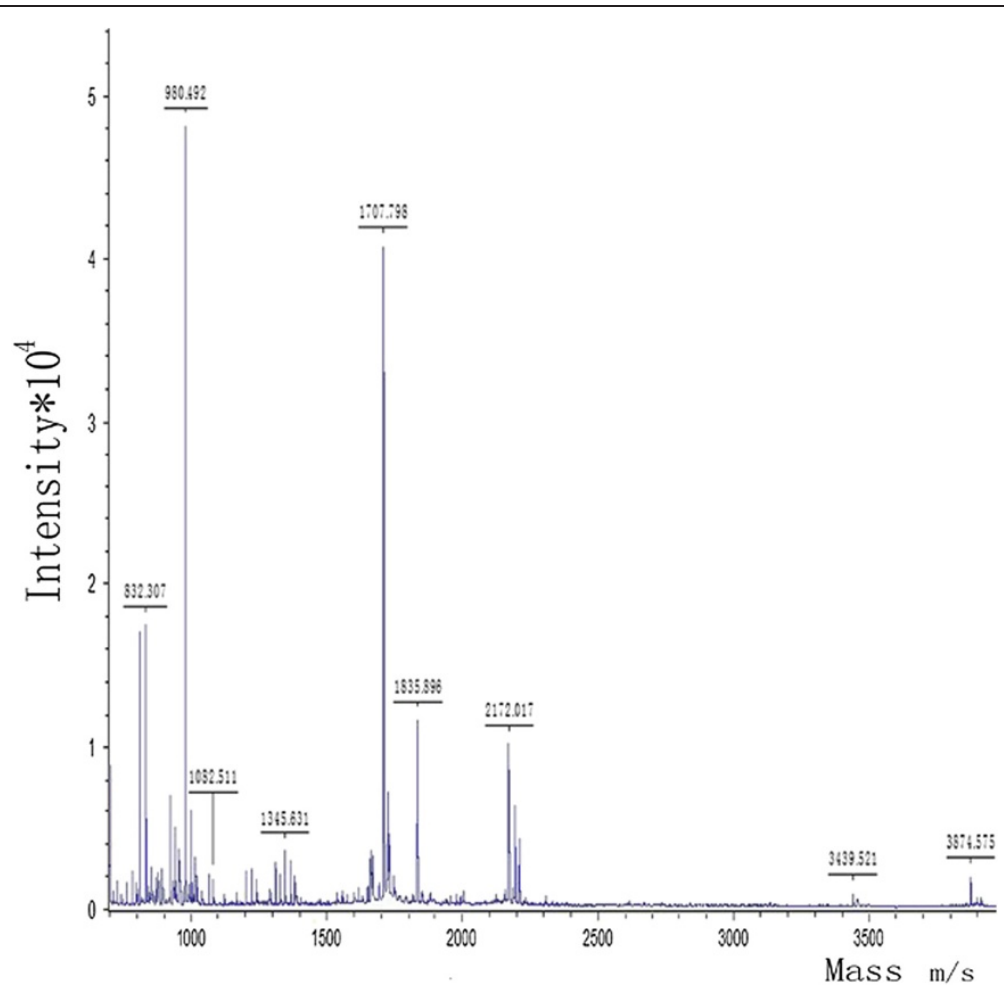

Figure 3 Representative MALDI-TOF peptide mass fingerprint spectrum of spot $\mathbf{b}$. After trypsin digestion, the resulting peptides were analysed by MALDI-MS and MS/MS analyses. Peptide mass fingerprints (PMFs) data were searched against the database of SwissProt by BioTools 3.0 software. The protein with molecular mass of approximately $42 \mathrm{kDa}$ was identified as haptoglobin (Hp) by the sequence analysis.

controls. For the purpose of identifying the potential biomarkers predicting long-term response to splenectomy in ITP patients, the present study carried out a comparative proteomics analysis with 2-DE and MS on the sera from the responders, nonresponders and healthy controls. Nine protein spots that were differentially expressed by at least

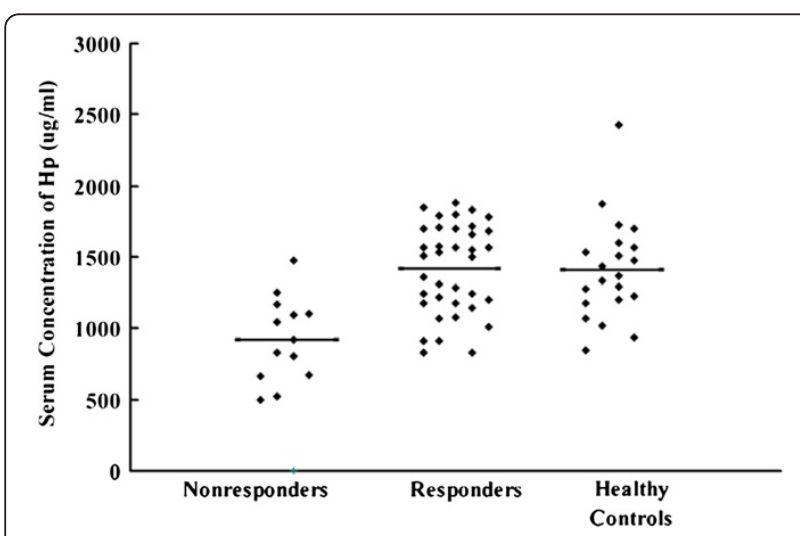

Figure 4 The preoperative serum level of $\mathrm{Hp}$ was validated by ELISA. One-way ANOVA analysis showed significant difference of preoperative serum $\mathrm{Hp}$ expressions among the three groups. The preoperative serum levels of $\mathrm{Hp}$ in thirteen nonresponders was significantly lower than that of thirty-seven responders $(p<0.001)$ and twenty-one healthy controls $(p<0.001)$. No significant difference was seen between the responders and healthy controls $(p>0.05)$.

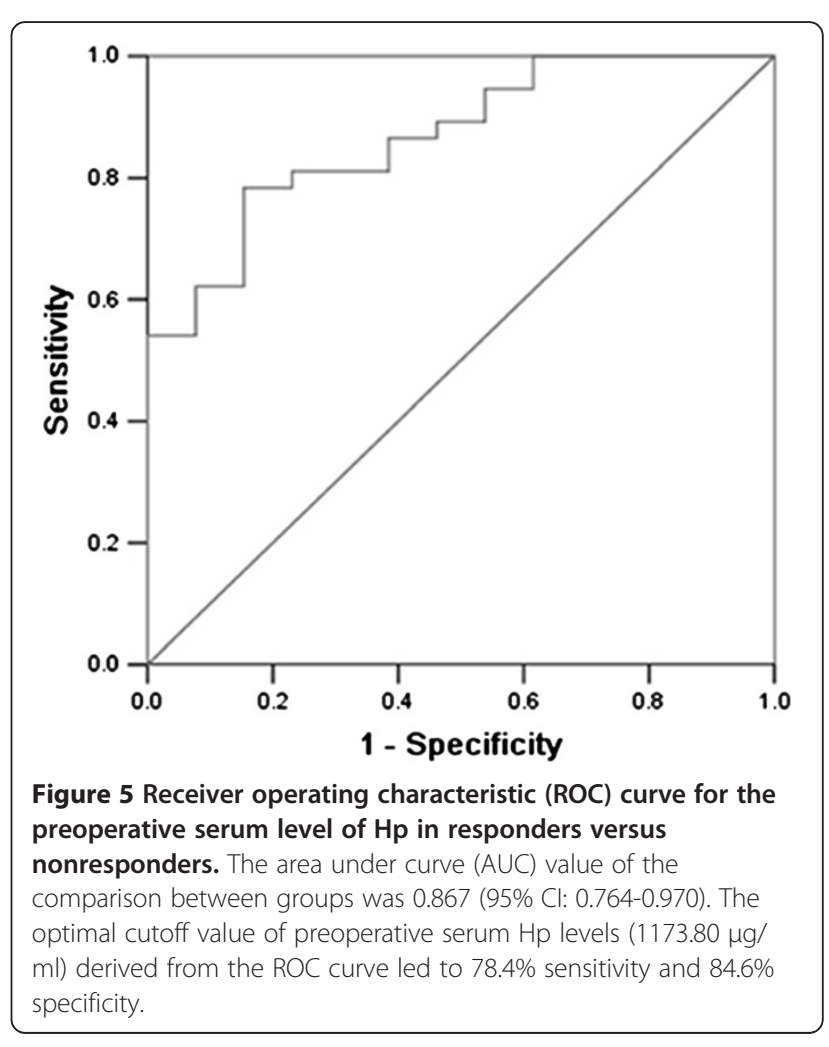




\begin{tabular}{|c|c|c|c|}
\hline Cutoff $(\mu \mathrm{g} / \mathrm{ml})$ & Sensitivity (\%) & Specificity (\%) & Youden index \\
\hline 816.42 & 100 & 38.5 & 0.385 \\
\hline 911.41 & 91.9 & 46.1 & 0.380 \\
\hline 1026.61 & 86.5 & 53.8 & 0.403 \\
\hline 1073.74 & 83.8 & 61.5 & 0.453 \\
\hline 1119.61 & 81.1 & 76.9 & 0.580 \\
\hline 1173.80 & 78.4 & 84.6 & 0.630 \\
\hline 1265.94 & 62.2 & 92.3 & 0.545 \\
\hline 1485.29 & 54.1 & 100 & 0.541 \\
\hline
\end{tabular}

five-fold between the responder and nonresponder samples were further analysed with MS/MS. All of the spots were identified as $\mathrm{Hp}$ by the peptide sequence analysis. Although the measurement of serum ceruloplasmin levels was found to be useful for the diagnosis of ITP in the report mentioned above, we did not identify ceruloplasmin as a highly differentiated expressed protein between responders and nonresponders in this study.

$\mathrm{Hp}$ is an acute phase protein that is synthesised predominately in the liver by hepatocytes. The major inducer of the expression of $\mathrm{Hp}$ is IL-6, which is produced through the activities of the primary cytokines TNF- $\alpha$ and IL-1 [19]. The serum levels of Hp remains fairly constant in any given individual; therefore, the observation of a marked change in serum $\mathrm{Hp}$ expression has clinical significance [20]. Hp consists of two different polypeptide chains, $\alpha$ chain and $\beta$ chain. There is only one type of $\beta$ chain with a MW of approximately 40 $\mathrm{kDa}$. However, the $\alpha$ chain is represented by two isoforms, $\alpha-1$ and $\alpha-2$, with the $\alpha-1$ isoform being approximately $9 \mathrm{kDa}$ and the $\alpha-2$ being $16 \mathrm{kDa}$ in MW [21]. After chemical reduction of $\mathrm{Hp}$, these polypeptide chains can be clearly revealed in the images of gel electrophoresis [21]. In this study, five protein spots with MW of $38.7-42.2 \mathrm{kDa}$, shown in region 1 of the 2-DE images, were identified as the $\beta$ chain of $\mathrm{Hp}$. While three protein spots in region $2(\mathrm{MW} 16.9-17.1 \mathrm{kDa})$ and one protein spot in region $3(\mathrm{MW} 11.9 \mathrm{kDa})$ represented the $\alpha-2$ and $\alpha-1$ isoforms of $\mathrm{Hp}$.

$\mathrm{Hp}$ has been proven to modulate both innate and adaptive immune responses in several aspects. Th1 and Th2 play a crucial role in the pathogenesis of autoimmune diseases [22]. Studies performed both in vitro and in vivo indicate that $\mathrm{Hp}$ exhibits a significant modulating impact on the Th1/Th2 balance via an inhibitory effect on Th2 cytokine release and therefore promotes a dominant Th1 cellular response [23,24]. Hp supports proliferation and functional differentiation of $\mathrm{B}$ and $\mathrm{T}$ cells as part of homeostasis and in response to antigen stimulation. Analysis of blood from $\mathrm{Hp}$-deficient mice showed a significant reduction in B and $\mathrm{T}$ lymphocytes, and the relative number of splenic monocytes and dendritic cells appeared elevated with respect to wild-type mice [25]. A more recent study showed that Hpdeficient mice facilitate the development of autoimmune disease of central nervous system, which is associated with the enhanced production of several inflammatory cytokines in the spinal cord [26]. Hp is characterised by molecular heterogeneity, with three major phenotypes: Hp 1-1, Hp 2-2, and the heterozygous Hp 2-1. The Hp 2-2 genotype was associated with decreased serum concentrations of Hp. A significant over-representation of the Hp 2-2 genotype has been shown in human immune disorders, such as rheumatoid arthritis, diabetes mellitus type 2, and inflammatory bowel diseases [27]. Taken together, these studies suggest that Hp may play an important role in the pathogenesis and clinical course of autoimmune diseases through various immunomodulatory effects. To date, very few studies in the current literature focused on the issue of the serum $\mathrm{Hp}$ expression in ITP patients. A recent study found that abnormally low levels of free serum Hp were present in eleven out of thirty paediatric patients with ITP [28]. The authors considered $\mathrm{Hp}$ as a sensitive indicator of haemolysis and presumed that patients with low levels of serum Hp may develop autoimmune haemolytic anaemia in long-term follow-up studies. Until now, the pathophysiological roles of Hp in ITP were poorly understood.

Recent proteomic studies showed that Hp served as an important biomarker in some autoimmune diseases. Increased protein levels of $\mathrm{Hp}$ were found in the cerebrospinal fluid from patients with Guillain-Barré syndrome, which is an acute inflammatory autoimmune disorder in the peripheral nervous system $[29,30]$. Other studies reported that elevated serum levels of Hp correlated with higher disease activity in systemic lupus erythematosus and active Behcet's disease [31,32]. In the present study, we studied the differentially expressed proteins in the serum of ITP patients with different responses to splenectomy using a comparative proteomics approach. Hp was identified as a highly differentially expressed protein between nonresponders and responders. Further validation by ELISA showed that the preoperative serum levels of $\mathrm{Hp}$ in the nonresponders were significantly lower than those in the responders and healthy controls. No statistical differences of preoperative serum $\mathrm{Hp}$ expression were observed between the responders and healthy controls. The results indicate that the preoperative serum levels of Hp may serve as an important predictor of long-term haematological response to splenectomy in ITP patients. Patients with lower preoperative serum levels of $\mathrm{Hp}$ tend to have a worse response to surgery when compared with those with higher preoperative serum levels. The ROC curve is 
a useful method for evaluating clinical usefulness of a biomarker. The ROC curve analysis showed that AUC of the preoperative serum $\mathrm{Hp}$ levels reached 0.867 , which means that the preoperative serum $\mathrm{Hp}$ levels can be used as a potential predictive biomarker. The Youden index has been demonstrated to be a preferred means of identifying the optimal cutoff value from the ROC curve [33]. Therefore the optimal cutoff value of the preoperative serum $\mathrm{Hp}$ levels $(1173.80 \mu \mathrm{g} / \mathrm{ml})$ was identified based on the the maximum Youden index in this study. At this cutoff value, the sensitivity was $78.4 \%$ and the specificity was $84.6 \%$. The present study also found that the serum Hp levels did not change seven days after surgery in both responders and nonresponders. To the best of our knowledge, this is the first paper reporting a potential serum biomarker for predicting the long-term response to splenectomy in ITP patients. However, potential limitations of this study must be considered. While the removal of abundant serum proteins would facilitate the discovery and detection of less abundant proteins, including disease associated markers. It should be noted that this technique remains controversial in biomarker discovery, as it may also remove other possibly more interesting proteins bound to the abundant proteins[34]. Since relapses of ITP may occur even two years after splenectomy, further studies with larger sample size and long-term follow-up are needed to confirm our findings. Evans syndrome which links to low serum level of $\mathrm{Hp}$ and poor response to splenectomy should be strictly excluded from the study.

\section{Conclusions}

Our previous study found that the postoperative peak platelet count was closely correlated with the long-term response of splenectomy in ITP patients [35]. Similar results were also shown in this study. However, this variable can only be obtained after surgery and is of no use for making the decision of therapeutics. The present study demonstrates that by using a proteomic approach, we are able to identify $\mathrm{Hp}$ as a potential serum biomarker, which may serve as a major predictor of longterm response to splenectomy in ITP patients. The preoperative serum levels of $\mathrm{Hp}$ were also shown to be positively correlated with postoperative peak platelet count in ITP patients. These findings may be critical for providing new insights into the pathogenic mechanisms of ITP and optimising the strategic choice of surgical intervention. Further research investigating the biology of $\mathrm{Hp}$ would help to understand the pathophysiological differences between responders and nonresponders.

\section{Abbreviations}

ITP: Primary immune thrombocytopenia; 2-DE: Two-dimensional gel electrophoresis; MALDI-TOF: Matrix-assisted laser desorption/ionisation timeof-flight; MS: Mass spectrometer; Hp: Haptoglobin; ELISA: Enzyme-linked immunosorbent assays; IEF: Isoelectric focusing; DTT: Dithiothreitol; IPG: Immobilized pH gradient; SDS: Sodium dodecyl sulphate; PMFs: Peptide mass fingerprints; pl: Isoelectric points; MW: Molecular weights.

\section{Competing interests}

The authors declare that they have no competing interests.

\section{Authors' contributions}

ZCX and JZQ performed the most of the experiments. Z $L$ assisted in experimental design and helped to interpret data.WQ participated in acquiring laboratory data analysis. CLH and YJF collected samples and helped to interpret data. ZCX and ZD designed research and wrote the manuscript. All authors read and approved the final manuscript.

\section{Acknowledgements}

This work was supported by grants from the Science and Technique Project of Guangdong Province, No. 2008 B080703033 and No. 2010B031600212, and a Grant from the Guangdong Natural Science Foundation of China, No. 9151008901000061.

\section{Author details}

${ }^{1}$ Department of Minimal Invasive Surgery, The First Affiliated Hospital, Sun Yat-sen University, Guangzhou 510080, China. ' Laboratory of Surgery, The First Affiliated Hospital, Sun Yat-sen University, Guangzhou 510080, China. ${ }^{3}$ Department of Medicine, The First Affiliated Hospital, Sun Yat-sen University, Guangzhou 510080, China. ${ }^{4}$ Department of Haematology, The First Affiliated Hospital, Sun Yat-sen University, Guangzhou 510080, China.

Received: 7 April 2012 Accepted: 2 October 2012

Published: 7 October 2012

\section{References}

1. Rodeghiero F, Stasi R, Gernsheimer T, Michel M, Provan D, Arnold DM, Bussel JB, Cines DB, Chong BH, Cooper N, Godeau B, Lechner K, Mazzucconi MG, McMillan R, Sanz MA, Imbach P, Blanchette V, Kuhne T, Ruggeri M, George JN: Standardization of terminology, definitions and outcome criteria in immune thrombocytopenic purpura of adults and children: report from an international working group. Blood 2009, 113:2386-2393.

2. Cooper N, Bussel J: The pathogenesis of immune thrombocytopenic purpura. Br J Haematol 2006, 133:364-374.

3. Kuwana M, Okazaki Y, Kaburaki J, Kawakami Y, Ikeda Y: Spleen is a primary site for activation of platelet-reactive $T$ and $B$ cells in patients with immune thrombocytopenic purpura. J Immunol 2002, 168:3675-3682.

4. Kojouri K, Vesely SK, Terrell DR, George JN: Splenectomy for adult patients with idiopathic thrombocytopenic purpura: a systematic review to assess long-term platelet count responses, prediction of response, and surgical complications. Blood 2004, 104:2623-2634.

5. Fabris F, Tassan T, Ramon R, Carraro G, Randi ML, Luzzatto G, Moschino P, Girolami A: Age as the major predictive factor of long-term response to splenectomy in immune thrombocytopenic purpura. Br J Haematol 2001, 112:637-640.

6. Katkhouda N, Grant SW, Mavor E, Friedlander MH, Lord RV, Achanta K, Essani $R$, Mason R: Predictors of response after laparoscopic splenectomy for immune thrombocytopenic purpura. Surg Endosc 2001, 15:484-488.

7. Kumar S, Diehn FE, Gertz MA, Tefferi A: Splenectomy for immune thrombocytopenic purpura: long-term results and treatment of postsplenectomy relapses. Ann Hematol 2002, 81:312-319.

8. Vianelli N, Galli M, de Vivo A, Intermesoli T, Giannini B, Mazzucconi MG, Barbui T, Tura S, Baccaranion M: Gruppo Italiano per lo Studio delle Malattie Ematologiche dell'Adulto: Efficacy and safety of splenectomy in immune thrombocytopenic purpura: long-term results of 402 cases. Haematologica 2005, 90:72-77.

9. Bourgeois E, Caulier MT, Delarozee C, Brouillard M, Bauters F, Fenaux P: Long-term follow-up of chronic autoimmune thrombocytopenic purpura refractory to splenectomy: a prospective analysis. Br J Haematol 2003, 120:1079-1088.

10. Radaelli F, Faccini P, Goldaniga M, Guggiari E, Pozzoli E, Maiolo AT, Ciani A, Pogliani EM: Factors predicting response to splenectomy in adult patients with idiopathic thrombocytopenic purpura. Haematologica 2000, 85:1040-1044 
11. Wu JM, Lai IR, Yuan RH, Yu SC: Laparoscopic splenectomy for idiopathic thrombocytopenic purpura. Am J Surg 2004, 187:720-723.

12. Balague C, Vela S, Targarona EM, Gich IJ, Muniz E, D'Ambra A, Pey A, Monllau V, Ascaso E, Martinez C, Garriga J, Trias M: Predictive factors for successful laparoscopic splenectomy in immune thrombocytopenic purpura: study of clinical and laboratory data. Surg Endosc 2006, 20:1208-1213.

13. Najean Y, Rain JD, Billotey C: The site of destruction of autologous $111 \mathrm{ln}$ labelled platelets and the efficiency of splenectomy in children and adults with idiopathic thrombocytopenic purpura: a study of 578 patients with 268 splenectomies. Br J Haematol 1997, 97:547-550.

14. British Committee for Standards in Haematology General Haematology Task Force: Guidelines for the investigation and management of idiopathic thrombocytopenic purpura in adults, children and in pregnancy. $\mathrm{Br} J$ Haematol 2003, 120:574-596.

15. Zhang D, Tai LK, Wong LL, Chiu LL, Sethi SK, Koay ES: Proteomic study reveals that proteins involved in metabolic and detoxification pathways are highly expressed in HER-2/neu-positive breast cancer. Mol Cell Proteomics 2005, 4:1686-1696.

16. Fathman CG, Soares L, Chan SM, Utz PJ: An array of possibilities for the study of autoimmunity. Nature 2005, 435:605-611.

17. Gibson DS, Banha J, Penque D, Costa L, Conrads TP, Cahill DJ, O'Brien JK, Rooney ME: Diagnostic and prognostic biomarker discovery strategies for autoimmune disorders. J Proteomics 2010, 73:1045-1060.

18. Chousa M, Ito H, Saito K, Takahashi K, Takemura M, Takahashi T, Tomita E, Seishima M: The measurement of serum ceruloplasmin is useful for diagnostic differentiation of immune thrombocytopenic purpura. Clin Chim Acta 2008, 389:132-138.

19. Oliviero S, Morrone G, Cortese R: The human haptoglobin gene: transcriptional regulation during development and acute phase induction. EMBO J 1987, 6:1905-1912.

20. Levy AP, Asleh R, Blum S, Levy NS, Miller-Lotan R, Kalet-Litman S, Anbinder Y, Lache O, Nakhoul FM, Asaf R, Farbstein D, Pollak M, Soloveichik YZ, Strauss M, Alshiek J, Livshits A, Schwartz A, Awad H, Jad K, Goldenstein H: Haptoglobin: basic and clinical aspects. Antioxid Redox Signal 2010 12:293-304

21. Langlois MR, Delanghe JR: Biological and clinical significance of haptoglobin polymorphism in humans. Clin Chem 1996, 42:1589-1600.

22. Singh VK, Mehrotra S, Agarwal SS: The paradigm of Th1 and Th2 cytokines: its relevance to autoimmunity and allergy. Immunol Res 1999, 20:147-161.

23. Arredouani MS, Kasran A, Vanoirbeek JA, Berger FG, Baumann H, Ceuppens JL: Haptoglobin dampens endotoxin-induced inflammatory effects both in vitro and in vivo. Immunology 2005, 114:263-271.

24. Guetta J, Strauss M, Levy NS, Fahoum L, Levy AP: Haptoglobin genotype modulates the balance of Th1/Th2 cytokines produced by macrophages exposed to free hemoglobin. Atherosclerosis 2007, 191:48-53.

25. Huntoon KM, Wang Y, Eppolito CA, Barbour KW, Berger FG, Shrikant PA, Baumann $\mathrm{H}$ : The acute phase protein haptoglobin regulates host immunity. J Leukoc Biol 2008, 84:170-181.

26. Galicia G, Maes W, Verbinnen B, Kasran A, Bullens D, Arredouani M, Ceuppens $\mathrm{JL}$ : Haptoglobin deficiency facilitates the development of autoimmune inflammation. Eur J Immunol 2009, 39:3404-3412.

27. Marquez L, Shen C, Cleynen I, De Hertogh G, Van Steen K, Machiels K, Perrier C, Ballet V, Organe S, Ferrante M, Henckaerts L, Galicia G, Rutgeerts P, Ceuppens $J$, Vermeire $S$ : Effects of haptoglobin polymorphisms and deficiency on susceptibility to inflammatory bowel disease and on severity of murine colitis. Gut 2012, 61:528-534.

28. Dash S, Marwaha R, Trehan A: Attenuated form of Evans syndrome among pediatric ITP patients. Indian Pediatr 2006, 43:340-343.

29. Chang KH, Lyu RK, Tseng MY, Ro LS, Wu YR, Chang HS, Hsu WC, Kuo HC, Huang CC, Chu CC, Hsieh SY, Chen CM: Elevated haptoglobin level of cerebrospinal fluid in Guillain-Barre syndrome revealed by proteomics analysis. Proteomics Clin Appl 2007, 1:467-475.

30. Jin T, Hu LS, Chang M, Wu J, Winblad B, Zhu J: Proteomic identification of potential protein markers in cerebrospinal fluid of GBS patients. Eur J Neurol 2007, 14:563-568.

31. Pavon EJ, Munoz P, Lario A, Longobardo V, Carrascal M, Abian J, Martin AB, Arias SA, Callejas-Rubio JL, Sola R, Navarro-Pelayo F, Raya-Alvarez E, OrtegoCenteno N, Zubiaur M, Sancho J: Proteomic analysis of plasma from patients with systemic lupus erythematosus: increased presence of haptoglobin alpha2 polypeptide chains over the alpha1 isoforms. Proteomics 2006, 6(Suppl 1):S282-S292.

32. Mao L, Dong H, Yang P, Zhou H, Huang X, Lin X, Kijlstra A: MALDI-TOF/ TOF-MS reveals elevated serum haptoglobin and amyloid $A$ in Behcet's disease. J Proteome Res 2008, 7:4500-4507.

33. Perkins NJ, Schisterman EF: The inconsistency of "optimal" cutpoints obtained using two criteria based on the receiver operating characteristic curve. Am J Epidemiol 2006, 163:670-675.

34. Qian WJ, Jacobs JM, Camp DG, Monroe ME, Moore RJ, Gritsenko MA, Calvano SE, Lowry SF, Xiao W, Moldawer LL, Davis RW, Tompkins RG, Smith RD: Comparative proteome analyses of human plasma following in vivo lipopolysaccharide administration using multidimensional separations coupled with tandem mass spectrometry. Proteomics 2005, 5:572-584.

35. Zheng CX, Zheng D, Chen LH, Yu JF, Wu ZM: Laparoscopic splenectomy for immune thrombocytopenic purpura at a teaching institution. Chin Med J (Engl) 2011, 124:1175-1180

\section{doi:10.1186/1479-5876-10-208}

Cite this article as: Zheng et al:: Proteomics-based identification of haptoglobin as a favourable serum biomarker for predicting long-term response to splenectomy in patients with primary immune thrombocytopenia. Journal of Translational Medicine 2012 10:208.

\section{Submit your next manuscript to BioMed Central and take full advantage of:}

- Convenient online submission

- Thorough peer review

- No space constraints or color figure charges

- Immediate publication on acceptance

- Inclusion in PubMed, CAS, Scopus and Google Scholar

- Research which is freely available for redistribution 